\author{
Асхабова $\Lambda$. М., \\ Сабиров А.Ф., \\ Унтилов Г.В., \\ Гаджиева $\Lambda . A$.
}

\begin{abstract}
Федеральное государственное бюджетное образовательное учреждение высшего образования "Аагестанский государственный медицинский университет" Минзарава России, 367000, г. Махачкала, Российская Федерация
\end{abstract}

Представлена информация об инфекции COVID-2019, вызванной коронавирусом SARS-CoV-2, до 26 июня 2020 г. в Республике Дагестан (РД).

Цель работы - систематизация статистической информации о заболеваемости коронавирусной инфекцией COVID-2019 с конца марта до конца июня 2020 г.

Материал и методы. Анализ заболеваемости и смертности проведен по данным статистических запросных форм, разработанных экспертной группой при Правительстве РД. Сформированные запросные формы предназначены для заполнения специалистами городских и районных администраций, в них были включены сведения о числе выявленных случаев заболевания новой коронавирусной инфекцией, распределении их по возрасту, степени тяжести течения и прогнозе болезни, о необходимости госпитализации и наличии согласия на госпитализацию.

Помимо этого, были сформированы запросные формы, которые позволили учесть обеспеченность средствами индивидуальной защиты на уровне районов и городов. Сбор статистических материалов был проведен во всех городах и районах РД.

Результаты. Проанализированы количественные показатели: число заболевших новой коронавирусной инфекцией, число выздоровевших, умерших, а также динамика развития эпидемии COVID-2019 в РД с оценкой эпидемической ситуации. Дана характеристика службы регионального здравоохранения в период эпидемии. В Дагестане на конец первого полугодия 2020 г. выявлено 8132 случая COVID-2019, выздоровевших - 6124, умерших - 391, из них 70 медиков. Среди российских регионов Дагестан находился на 5-м месте по числу инфицированных COVID-19. В эпидемический процесс были вовлечены 43 муниципальных образования республики. Из общего числа заболевших городские жители составили 59,0\%, сельские - 41,0\%. Было проведено 173500 тестов, 44,0\% положительных на COVID-19 выявлены активно при обследовании контактных людей в эпидемических очагах и 56,0\% - при обращении за медицинской помощью с острыми респираторными вирусными инфекциями и внебольничными пневмониями. Из 1231 выявленного случая с диагнозом COVID-19 были госпитализированы 944 (76,7\%) человека, в том числе с бессимптомным течением - 414 (33,6\%) человек, с легкой формой (острая респираторная вирусная инфекция) - 205 (16,7\%), с внебольничной пневмонией средней тяжести - 518 (42,1\%), с внебольничной пневмонией тяжелой формы - 94 (7,6\%).

Заключение. Стремительно нарастающие показатели заболеваемости и летальности стали основанием для создания по инициативе Правительства РД экспертной аналитической группы, которая предложила проведение рандомизированного исследования при сравнении статистических данных, поступающих от руководителей городских и районных муниципальных образований с данными медицинских организаций Минздрава РД. Анализ выявил заметные различия в абсолютных и относительных величинах распространенности коронавирусной инфекции.

17 мая пресс-центр Минздрава РД опубликовал статистические данные, согласно которым в Дагестане выявлено 13697 случаев внебольничной пневмонии (на тот момент в регионе официально было только 3280 больных новой коронавирусной инфекцией). Погибли от пневмонии (без учета коронавирусной этиологии болезни) 657 человек, в том числе более 70 врачей, которые своевременно не были обеспечены необходимыми средствами индивидуальной защиты.

Был выявлен тотальный дефицит коечной мощности инфекционного профиля, обеспеченности лекарственными препаратами и средствами индивидуальной защиты. В результате в РД были дополнительно перепрофилированы в инфекционные 2572 койки в 20 стационарах (из них 278 коек с искусственной вентиляцией легких, 700 коек с подведенным кислородом). ключевые слова: коронавирус, коронавирусная инфекция, COVID-2019, SARS-CoV-2, 2019-nCoV, пневмония, безопасность 
Финансирование. Исследование не имело спонсорской поддержки.

Конфликт интересов. Авторы заявляют об отсутствии конфликта интересов.

Вклад авторов. Концепция и дизайн исследования - Асхабова Л.М., Сабиров Л.Ф.; сбор и обработка материала - Гаджиева Л.А., Унтилов Г.В.

Для цитирования: Асхабова Л.М., Сабиров Л.Ф., Унтилов Г.В., Гаджиева Л.А. COVID-2019 в Республике Дагестан // Инфекционные болезни: новости, мнения, обучение. 2020. Т. 9, № 4. С. 46-53. D0I: https://doi.org/10.33029/2305-3496-2020-9-4-46-53 Статья поступила в редакцию 21.10.2020. Принята в печать 09.11.2020.

\section{COVID-2019 in the Republic of Dagestan}

Askhabova L.M., Sabirov L.F., Untilov G.V., Gadzhieva L.A.
Dagestan State Medical University, 367000, Makhachkala, Russian Federation
Information is provided on the COVID-2019 infection caused by the SARS-CoV-2 coronavirus until June 26, 2020 in the Republic of Dagestan.

The aim - systematization of information on coronavirus infection COVID-2019 from the end of March to the end of June 2020.

Material and methods. An expert group was created under the Government of the Republic of Dagestan, which prepared statistical models for the formation of requests from specialists of city and district administrations on the following issues: incidence of coronavirus infection in sections: identification, classification by age, severity, the need for hospitalization and consent to hospitalization , prognosis of the course of the disease. In addition to the analysis of morbidity and mortality, inquiry forms were developed, which made it possible to take into account the issues of the provision of personal protective equipment at the level of districts and cities. All cities and regions of the Republic of Dagestan were identified as observation bases.

Results. The dynamics of the number of cases, recovered and deaths, the chronicle of the COVID-2019 epidemic in the republic caused by the SARS-CoV-2 coronavirus, and an assessment of the epidemic situation are presented. The characteristics of the regional health service during the epidemic are given. The spread of coronavirus in Dagestan at the end of the first half of 2020 was 8132 cases, recovered - 6124 cases, recorded deaths - 391, of which: doctors -70 people. By the end of the first half of 2020, Dagestan was in 5th place in terms of the number of COVID-19 infected among Russian regions. 173500 test controls were carried out. 43 municipalities of the republic were involved in the epidemic process, including: urban residents accounted for $59.0 \%$; rural residents $41.0 \%$. Among the surveyed, $44.0 \%$ were identified actively during examination of contact persons and $56.0 \%$ were identified when seeking medical help with ARVI and community-acquired pneumonia. Of the 1231 cases identified with the diagnosis of COVID-19, 944 (76.7\%) people were hospitalized, including: asymptomatic - 414 (33.6\%) people, with mild (ARVI) - 205 (16.7\%) people, with community-acquired pneumonia of moderate severity $-518(42.1 \%)$ people, with community-acquired pneumonia of severe form - $94(7.6 \%)$ people.

Conclusion. The rapidly increasing dynamics of morbidity and mortality prompted the creation, at the initiative of the Government of the Republic of Dagestan, of an expert analytical group, which proposed conducting a randomized study when comparing statistical data received from heads of city and district municipalities with data from medical organizations of the Ministry of Health of the Republic of Dagestan. The analysis revealed significant differences in the absolute and relative values of the prevalence of coronavirus infection.

On May 17, the press center of the Ministry of Health of the Republic of Dagestan published that 13697 people are sick with coronavirus and "community-acquired pneumonia" in Dagestan (at that time there were officially only 3280 patients with coronavirus in the region). Died from pneumonia (excluding coronavirus) 657 , including more than 70 people - doctors who were not timely provided with the necessary personal protective equipment.

The problem of a total shortage of bed capacity of an infectious profile, the provision of medicines and personal protective equipment has also been exposed. As a result, 2572 beds in 20 hospitals were additionally redesigned in the republic (of which: 278 beds with mechanical ventilation, 700 beds - with supplied oxygen).

Funding. The study had no sponsor support.

Conflict of interests. The authors declare no conflict of interests.

Contribution. Research concept and design - Askhabova L.M., Sabirov L.F.; collection and processing of material - Gadzhieva L.A., Untilov G.V.

For citation: Askhabova L.M., Sabirov L.F., Untilov G.V., Gadzhieva L.A. Statistics of the coronavirus COVID-2019 in the Republic of Dagestan. Infektsionnye bolezni: novosti, mneniya, obuchenie [Infectious Diseases: News, Opinions, Training]. 2020; 9 (4): 46-53. DOI: https://doi.org/10.33029/2305-3496-2020-9-4-46-53 (in Russian)

Received 21.10.2020. Accepted 09.11.2020.

\section{Keywords:}

coronavirus,

coronavirus

infection,

COVID-2019,

SARS-CoV-2,

2019-nCoV,

pneumonia, safety 
C реди показателей, определяющих здоровье населения, ведущее место принадлежит заболеваемости, являющейся не столько следствием медико-организационных факторов, сколько отражением популяционного итога взаимодействия социально-гигиенических, медико-биологических, экологических, экономических и других факторов. Заболеваемость играет многогранную роль в определении благополучия населения. С одной стороны, она наиболее точно характеризует состояние здоровья населения, уровень жизни, а с другой - свидетельствует об эффективности деятельности федеральных и региональных служб здравоохранения. Эта дефиниция является чувствительным индексом социально-экономических изменений. Структура потерь здоровья определяется прежде всего хроническими заболеваниями, и при сравнительном анализе напрашивается вывод о том, что во всех случаях показатели довольно значимые. В наибольшей степени тяжесть заболевания и вероятность летального исхода определяют наличие у пациентов сочетанных хронических заболеваний и вирусной инфекции.

Вспышка новой так называемой коронавирусной инфекции возникла в декабре 2019 г. в г. Ухань (Китай) с дальнейшим пандемическим распространением. Генеральный директор В03 Тедрос Адан Гебреисус провел 22 и 23 января 2020 г. экстренное заседание Чрезвычайного комитета в рамках Международных медико-санитарных правил по пневмонии, вызванной новым коронавирусом 2019-nCoV (ЧК ММСП). По итогам первого заседания вспышка пневмонии не была объявлена чрезвычайной ситуацией санитарноэпидемиологического характера, имеющей международное значение, так как большинство заболевших было локализовано в Китае [1-3].

24 января 2020 г. Роспотребнадзор разместил на своем веб-сайте постановление Главного санитарного врача России от 24.01.2020 № 2 «0 дополнительных мероприятиях по недопущению завоза и распространения новой коронавирусной инфекции, вызванной 2019-nCoV» [1, 2].

Минздрав России 25 января 2020 г. опубликовал на своем веб-сайте презентацию «Информация о новой коронавирусной инфекции, вызванной 2019-nCoV». Руководители Минздрава России и Роспотребнадзора утвердили 30 января 2020 г. первую версию временных методических рекомендаций «Профилактика, диагностика и лечение новой коронавирусной инфекции (2019-nCoV)» [1]. 30 января 2020 г. на заседании ЧК ММСП В03 эпидемия, вызванная коронавирусом 2019-nCoV, была объявлена «чрезвычайной ситуацией в здравоохранении, имеющей международное значение» [4]. 11 февраля 2020 г. новая коронавирусная инфекция получила название Coronavirus Disease 2019 (COVID-2019), а вызывающий ее вирус был переименован в Severe acute respiratory syndrome coronavirus 2 (второй коронавирус тяжелого острого респираторного синдрома, SARS-CoV-2) [3].

Эпидемия COVID-19 уже вошла в историю как чрезвычайная ситуация международного значения. Наибольшее число случаев новой коронавирусной инфекции, по данным за первое полугодие 2020 г., было зарегистрировано в зимнее и весеннее время.
Источники инфекции - больные и носители. Пути передачи возбудителя - воздушно-капельный и контактнобытовой.

Были описаны основные клинические признаки COVID-19. Лихорадочно-интоксикационный синдром: лихорадка (у 87,9\% обратившихся за медицинской помощью), обычно субфебрильная температура (до $37,5{ }^{\circ} \mathrm{C}$ у $56,2 \%$ ), усталость и слабость (38,1\%), головная боль $(13,6 \%)$; респираторный синдром - кашель $(67,7 \%)$; в тяжелых случаях одышка $(18,6 \%)$, а также диспепсия (5\%) и диарея $(3,7 \%)$. Наиболее частые проявления тяжелых случаев COVID-19: пневмония $(76 \%)$ и гипоксия $(38 \%)[3,4]$.

Определены клинические формы COVID-19:

- бессимптомная (у 1-3\% больных);

- легкая (с поражением только верхних дыхательных путей);

- среднетяжелая (пневмония без дыхательной недостаточности);

- тяжелая (пневмония с развитием дыхательной недостаточности, частота дыхательных движений >30 в минуту, сатурация $<93 \%$, индекс оксигенации $\mathrm{PaO}_{2} / \mathrm{FiO}_{2}$ $<300$, или появление инфильтратов в легких в виде «матового стекла», занимающих более 50\% легких в течение 24-48 ч);

- очень тяжелая (критическая) форма (пневмония, сепсис, септический шок, полиорганная недостаточность).

Вероятность летального исхода при COVID-2019 пропорциональна возрасту пациентов: чем старше пациент, особенно при наличии у него сочетанной патологии, тем тяжелее исходы заболевания. Приблизительно 10-15\% легких и среднетяжелых случаев (81-82\% всех инфицированных) переходят в тяжелые. Около 15-20\% тяжелых случаев становятся очень тяжелыми.

К категории высокого риска летальности от COVID-2019 следует отнести пожилых пациентов с сопутствующими заболеваниями.

В рассматриваемый период по числу зараженных Россия находилась на 3-м месте в мире после США и Бразилии, а Республика Дагестан (РД) по этому показателю занимала 5-е место среди всех регионов России.

Цель работы - анализ статистической информации о коронавирусной инфекции COVID-19 в РД с конца марта до конца июня 2020 г.

\section{Материал и методы}

В связи с осложнением эпидемической ситуации по коронавирусной инфекции COVID-2019 с начала марта 2020 г. при Правительстве РД была создана экспертная группа, которая в ходе работы подготовила статистические модели для формирования запросов специалистов городских и районных администраций по следующим вопросам: заболеваемость коронавирусной инфекцией в разрезах: выявление, классификация по возрастам, степени тяжести, необходимости госпитализации и согласия на госпитализацию, прогнозы течения заболевания. Помимо анализа заболеваемости и смертности, были разработаны запросные 
формы, которые позволили учесть вопросы обеспеченности средствами индивидуальной защиты на уровне районов и городов.

Таким образом, базами наблюдения были определены все города и районы РД.

В республике функционировал многоканальный номер (8-800-350-00-63), по которому можно было получить информацию по линии работы каждого задействованного ведомства. Телекоммуникационная линия была организована таким образом, чтобы несколько абонентов могли в одно и то же время дозвониться по единому номеру. Для этого в администрации главы РД и Правительства РД был создан ситуаци онный центр, куда стекалась вся информация и где осуществлялся контроль за исполнением поручений по данной теме. В круглосуточном режиме на звонки отвечали операторы. Таким образом, информация о числе зараженных, умерших и выздоровевших от COVID-19 в РД получена с сайтов: https:// koronainfo.ru/dagestan $и$ https://gogov.ru/covid-19/dg [1].

\section{Результаты и обсулкиение}

Дагестан оказался в первой десятке российских регионов, наиболее пострадавших от коронавирусной инфекции. Согласно статистике, число заболевших новой коронавирусной инфекцией в РД на конец первого полугодия 2020 г. составляло 8132, выздоровевших - 6124; зафиксированных смертей - 391, из них медиков - 70. Таким образом, РД к концу первого полугодия 2020 г. находилась на 5-м месте среди административных территорий Российской Федерации по числу инфицированных COVID-19, уступая лишь Москве, Московской области, Санкт-Петербургу и Нижегородской области. На борьбу с коронавирусом в РД было направлено 4,8 млрд руб. По региону было проведено 173500 тестов на COVID-19 [5].

На рисунке приведены данные о количестве зараженных, умерших и выздоровевших от COVID-19 в РД в динамике с охватом периода с 27 марта по 30 июня 2020 г. За анализируемый период число случаев заражения увеличилось от 1 до 7840. Из 96 дней наблюдения в 35 ежедневный прирост числа инфицированных превышал 100 случаев. Максимальный прирост числа зараженных отмечен 6 мая 181 случай. Начиная с 6 июня отмечено постепенное снижение ежедневного числа зараженных.

В РД с 23 марта по 28 апреля 2020 г. было получено 1147 положительных результатов тестов на COV1D-19, из них у медицинского персонала - 251 (74 работников COVID-19 центров), случаи заражения зарегистрированы в 10 городах и 31 районе республики (в 9 районах не зафиксировано заражений).

Число госпитализированных с положительным результатом теста на конец апреля составило 263 человека (793 отказались от госпитализации), из них 36 были подключены к аппаратам искусственной вентиляции легких (ИВЛ). Зарегистрировано 11 случаев с летальным исходом, с выздоровлением - 88 случаев. Показатель заболеваемости составил 36,87 на 100 тыс. населения (34-е место в Российской Федерации). Также с начала апреля зафиксировано 4955 случаев заболевания пневмонией (за 27 апреля 2020 г. 580 случаев).

На начало мая в республике были госпитализированы 4172 больных пневмонией, из них 2112 человек с подозрением на пневмонию, вызванную новым коронавирусом (в 7 районах не зафиксированы заболевания пневмонией). Из всех госпитализированных 166 человек находились в реанимации (44 человека старше 65 лет); 80 человек получали увлажненный кислород, 106 человек были подключены к аппаратам ИВЛ.

Первые умершие от COVID-19 в РД (3 человека) были зарегистрированы 15 апреля. К 30 июня их было 374 человека.

Первые выздоровевшие зарегистрированы 6 апреля 4 человека. K 30 июня число выздоровевших составило 5775 человек.

Показатель заболеваемости на конец апреля составил 39,7 на 100 тыс. населения.

28 апреля было зарегистрировано 84 новых случаев COVID-19: 51 (60,7\%) случай - с первичным диагнозом внебольничной пневмонии, 15 (17,8\%) случаев - ОРВИ, $18(21,4 \%)$ случаев - бессимптомные формы.

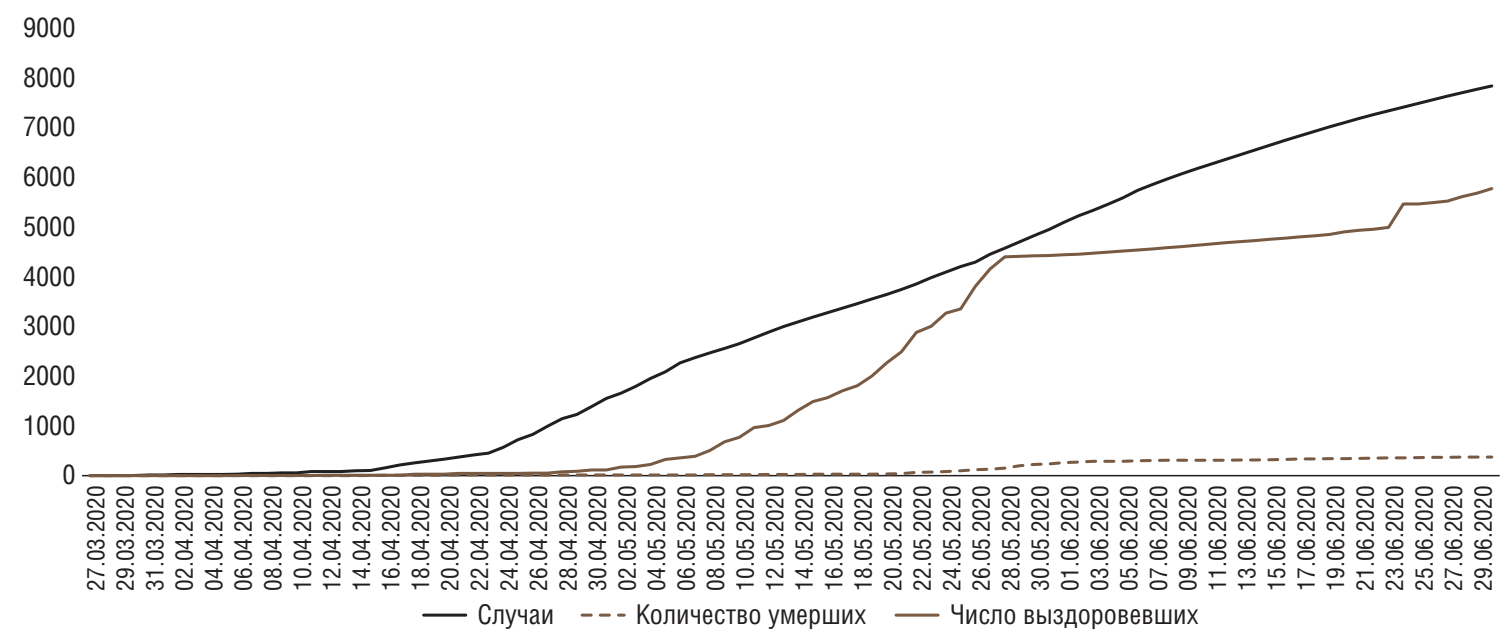

Количество зараженных, умерших и выздоровевших от COVID-19 в Республике Аагестан за период с 27 марта 2020 г. по 30 июня 2020 г. 
Стремительно нарастающие показатели заболеваемости и летальности стали основанием для создания по инициативе Правительства РД экспертной аналитической группы, которая предложила проведение рандомизированного исследования при сравнении статистических данных, поступающих от руководителей городских и районных муниципальных образований с данными медицинских организаций Минздрава РД. Проведенный анализ выявил заметные различия в абсолютных и относительных величинах распространенности коронавирусной инфекции.

17 мая пресс-центром Минздрава РД было опубликованы статистические материалы, согласно которым внебольничной пневмонией в Дагестане болеют 13697 человек (на тот момент в регионе официально было только 3280 больных новой коронавирусной инфекцией). Погибли от пневмонии (без учета COVID-19) 657 человек, в том числе более 50 врачей, которые своевременно не были обеспечены необходимыми средствами индивидуальной защиты.

Опубликованные данные стали национальной сенсацией: на 14 мая по официальной статистике, которую ежедневно публикует Роспотребнадзор РД, в республике были зарегистрированы всего 27 умерших.

Анализ, проведенный экспертной группой, позволил выявить проблему тотального дефицита коечной мощности инфекционного профиля, обеспеченности лекарственными препаратами и средствами индивидуальной защиты.

В эпидемический процесс были вовлечены 43 муниципальных образования республики, среди заболевших COVID-19 городские жители составили 59,0\%; сельские жители - 41,0\%. При обследовании контактных людей в эпидемических очагах активно были выявлены 44,0\% инфицированных, а 56,0\% - при обращении за медицинской помощью с ОРВИ и внебольничными пневмониями.

Среди 1231 больных с диагнозом COVID-19 были госпитализированы 944 (76,7\%) человека, в том числе с бессимптомным течением - 414 (33,6\%) человек, с легкой формой (ОРВИ) - 205 (16,7\%), с внебольничной пневмонией средней тяжести - $518(42,1 \%)$, с внебольничной пневмонией тяжелой формы - 94 (7,6\%).

Проведено обследование 1158 домашних очагов, из них: 41 семейно-квартирных с множественными случаями заболеваний; по одному очагу с 8, 7, 5, 4 и 3 заболевшими, 27 очагов с 2 заболевшими и 1117 очагов - с единичными случаями заболевания.

Во всех очагах обследованы контактные люди (94,3\%), проведен комплекс противоэпидемических мероприятий.

Таким образом, на конец мая текущего года в республике было зафиксировано 930 домашних и 5 коллективных очагов заражения.

Лабораторную диагностику новой коронавирусной инфекции проводили в 7 лабораториях, из них 3 лаборатории Роспотребнадзора РД, 4 лаборатории государственных медицинских организаций.

По сводкам Минздрава РД было отмечено, что на конец мая 2020 г. в регионе в 3 раза выросли объемы проводимых тест-исследований на новую коронавирусную инфекцию. «...На сегодняшний день в республике проводится порядка 2200 тестирований на COVID-19 в смену и их объемы будут еще наращивать», - сообщили в пресс-службе, подчеркнув, что специалистами республиканского Минздрава достигнута договоренность с производителями тест-систем о дополнительных поставках в республику.

За период мониторинга лабораториями по ПЦРдиагностике в РД было проведено 18475 исследований. Количество обследованных составило 16920 человек.

В настоящее время РД располагает 1556 койками для больных COVID-19 (по нормативу - 1556, исполнение 100\%), в том числе 545 койками с кислородной поддержкой без ИВЛ (по нормативу - 545 коек, исполнение - 100\%) и 544 койки с ИВЛ (по нормативу 544 койки, исполнение $100 \%)$.

В связи с ростом заболеваемости внебольничной пневмонией в РД дополнительно перепрофилированы 2572 койки в 20 стационарах (из них 278 коек с ИВЛ, 700 коек - с подведенным кислородом). (формирован резерв для развертывания дополнительных 595 коек для больных внебольничной пневмонией, в том числе государственные - 100 коек на базе ГБУ РД «Новолакская районная больница № 1»; 35 коек на базе ГБУ РД «Сулакская участковая больница» в пос. Сулак; частные - 160 коек ЧУз «Клиническая больница РЖДМедицина», г. Махачкала, 100 коек - АНО «Городская больница № 3», г. Махачкала, 200 коек - АМНО «Центр медицины высоких технологий им. И.Ш. Исмаилова», г. Махачкала. Был проработан вопрос разворачивания дополнительного коечного фонда с использованием мощностей спорткомплексов, помещений гостиниц и туристических баз, общежитий вузов. Всего при необходимости может быть развернуто около 3000 коек.

По данным Минздрава РД, до 1 мая 2020 г. в республике были развернуты койки для больных COVID-19 в 28 медицинских организациях, однако из-за большого потока пациентов и дефицита профильных коек буквально за несколько дней удалось довести общее число перепрофилированных медицинских организаций до 69, в их числе 4 частные больницы. К работе подключились АНО «Городская клиническая больница № 3», чУЗ «Клиническая больница РЖД-Медицина», 000 «Медицинский центр ЭОС» и АМНО «Центр медицины высоких технологий им. И.Ш. Исмаилова». Общее количество предоставленных данными клиниками коек достигло 505, остальные 7758 коек - база государственных медучреждений.

В связи с ростом заболеваемости коронавирусной инфекцией в республике возникла необходимость дифференцировать коечный фонд. К примеру, в ГБУ РД «Детская республиканская больница восстановительного лечения» направляли пациентов, находящихся в удовлетворительном состоянии для долечивания, где они находились под круглосуточным наблюдением врачей и среднего медперсонала. Таким образом, освобождались койки с подводом кислорода и всем необходимым для лечения более тяжелых пациентов. Для этих же целей 75 коек безвозмездно предоставил санаторий «Энергетик», куда на долечивание направлялись пациенты ГБУ «Центральная городская больница» г. Каспийска.

Таким образом, на конец мая 2020 г. в республике удалось развернуть 8263 койки. Кроме того, распоряжением Правительства РФ Дагестану выделено 402 млн руб. на осна- 
щение дополнительного коечного фонда, из них заключень контракты на 209,3 млн руб., кассовое исполнение составляет 89,5 млн руб.

В связи со вспышкой COVID-19 в Дагестане, ростом заболеваемости и смертности в конце мая по поручению Президента РФ В.В. Путина в республику были направлены эксперты Минздрава России, Роспотребнадзора, Росздравнадзора, Правительства РФ; для оказания медицинской помощи больным новой коронавирусной инфекцией выделено 842,8 млн руб.

По поручению Президента РФ распоряжением от 22.05.2020 № 208 руководством РД были переданы Минобороны России в безвозмездное пользование 3 земельных участка, расположенных в Хасавюртовском районе и в Каспийске и Дербенте общей площадью более 70 тыс. м² для строительства 3 инфекционных госпиталей. Также силами Минобороны России были развернуты полевые госпитали на 200 мест в г. Буйнакске и в с. Ботлих.

Заводом «Дагдизель» разработана схема и ведется производство клапанов для организации подачи кислорода в медицинских учреждениях республики. Кислородом обеспечено более 700 коек.

Совместно с Минпромторгом России прорабатывается вопрос организации производства аппаратов ИВЛ на базе ОАО «Концерн КЭМЗ». В современных условиях развертывание производства дефицитной продукции на производственной базе СКФО позволит не только улучшить ситуацию с обеспеченностью аппаратами ИВЛ в округе, но и создать дополнительные рабочие места.

С Минпромторгом России проработан вопрос о поставке в Дагестан 171 аппарата ИВЛ. По разъяснениям ведомства, график поставок формируется с учетом складывающейся эпидемической обстановки в регионах. К сожалению, в РД до начала июля 2020 г. сохранялась крайне тревожная ситуация, наблюдался значительный рост больных не только коронавирусом, но и пневмонией другой этиологии.

Для оказания скорой медицинской помощи больным COVID-19 в РД имеется 591 автомобиль и задействованы 189 бригад скорой медицинской помощи. В этой части подспорьем стало приобретение новых автомобилей скорой помощи в 2019 г. (за счет республиканского бюджета - 108 машин, федерального - 42 машины). В июне 2020 г. были закуплены за счет региональных средств 14 машин скорой помощи. Всего до конца года планируется закупить дополнительно 47 машин скорой помощи, в том числе 17 за счет регионального бюджета и 30 за счет федерального бюджета, а также 56 машин неотложной помощи (региональный бюджет).

В целях оказания дополнительной поддержки людям пожилого возраста, инвалидам и гражданам, отнесенным к группе риска, организована доставка продуктов питания и предметов первой необходимости. Привлечено 2437 волонтеров, которые оказали помощь более 40000 гражданам.

На особом контроле находится вопрос обеспеченности лекарственными препаратами (противовирусные и антибактериальные препараты). 25 апреля из резервного фонда республики было дополнительно выделено 233 млн руб. на закупку препаратов. При этом на рынке по настоящее время продолжает сохраняться острый дефицит препаратов, предусмотренных клиническими рекомендациями по диагностике и лечению новой коронавирусной инфекции.

В целях обеспечения бесперебойной закупки необходимых средств индивидуальной защиты, дезинфицирующих средств и медицинского оборудования также в резервном фонде Правительства РД предусмотрено 375 млн руб. $(75+$ 300 млн руб.), из них 166 млн руб. уже законтрактованы.

Не осталась без внимания и тема медицинских масок. Они централизованно были закуплены Минпромторгом России. Дагестан получил 318000 масок. На эти цели было потрачено свыше 10 млн руб. из резервного фонда МЧС.

Индустриально-промышленный колледж г. Избербаша запустил производство марлевых медицинских масок, причем необходимый материал для работы был приобретен за внебюджетные средства. Ими были обеспечены люди старшего поколения, социальные работники и др. Эти средства защиты распределялись в первую очередь по местам массового скопления граждан и выдавались тем специалистам, которые ежедневно контактировали с большим количеством людей.

Также в республике задействованы собственные производственные мощности: 8 колледжей и учреждения Управления Федеральной службы исполнения наказаний ежедневно шьют около 14 тыс. марлевых масок. На фабрике «Лавантель» (г. Хасавюрт) ежедневно производится около 2000 противочумных костюмов.

Что касается средств индивидуальной защиты (СИЗ), то Дагестан получил их более 1000 , в том числе защитные костюмы, респираторы и медицинские защитные очки. В Управление Роспотребнадзора по РД поступили дополнительные СИЗ, жизненно необходимые для обеспечения безопасности сотрудников ведомства, организующих противоэпидемические мероприятия в период пандемии.

Гуманитарный груз, прибывший из Москвы, включал более 1000 СИЗ, в том числе высокотехнологичные защитные костюмы, респираторы уровня FFP2 и медицинские защитные очки. Поддержка была оказана рабочей группой, созданной при Постпредстве РД при Президенте РФ.

В связи с ростом заболеваемости и смертности от COVID-19 Минздрав России взял на контроль ситуацию с лекарственным обеспечением пациентов с коронавирусной инфекцией. В республику стали поступать необходимые лекарственные препараты, используемые для лечения коронавирусной инфекции, в связи с чем потребность в лекарственных препаратах была удовлетворена. Кроме того, обсуждался вопрос о возможности включения медицинских организаций республики в клинические исследования перспективных лекарственных препаратов, предварительно показавших эффективность в лечении COVID-19.

Соответствующие решения были приняты Минздравом России по итогам визита в РД группы экспертов Минздрава России и Росздравнадзора.

Дагестан получил партию необходимых лекарственных препаратов для лечения пациентов с коронавирусной инфекцией. Также, согласно заключению экспертов Минздрава России, медицинские организации республики могут включить в клинические исследования перспективных лекарственных препаратов от коронавирусной инфекции, 
предварительно показавших эффективность в ее лечении. Минздрав России уже направил в республику необходимые медикаменты, используемые для лечения COVID-19. Таким образом, потребность в них будет полностью удовлетворена. Решается и вопрос обеспечения препаратами пациентов, находящихся на амбулаторном лечении.

В связи со сложившейся эпидемической ситуацией 0перативным штабом 17 апреля 2020 г. были введены дополнительные ограничительные меры по обеспечению изоляции продолжительностью 14 дней для граждан, прибывающих из Москвы и Санкт-Петербурга. В рамках санитарной охраны территории были проведены следующие мероприятия: с 28 марта 2020 г. в международном аэропорту Махачкалы организовано проведение дистанционной термометрии и анкетирования пассажиров на внутренних рейсах, прибывающих из Москвы с дополнительным привлечением студентов медико-профилактического факультета ФГБОУ ВО ДГМУ Минздрава России. За период контроля были осмотрены 18439 человек, из них выявлены и госпитализированы в инфекционный стационар 28 человек с повышенной температурой тела и признаками респираторного заболевания, от которых получено 2 положительных результата исследования на COVID-19. Вручено 8092 постановления об изоляции на дому граждан. Находились на изоляции 2629 человек.

Для обеспечения изоляции и медицинского наблюдения в течение 14 дней в условиях обсерватора всех людей, вернувшихся в Российскую Федерацию и прибывших в аэропорт Махачкалы, направляли в развернутый обсерватор на базе 000 «Санаторий “Леззет"» на 156 мест. Медицинское обслуживание изолированных было организовано силами медперсонала ГБУ РД «Карабудахкентская ЦРБ». С 3 по 16 апреля находились на обсервации 24 человека. Выписаны по окончании медицинского наблюдения с отрицательными результатами обследования. С 22 апреля помещены под обсервацию в санаторий «Леззет» на 14 дней 133 человек, прибывших из Саудовской Аравии, и 17 человек из Азербайджана. В обсерваторе находились 150 человек, 24 апреля - 127 граждан РФ, которые прибыли через границу с Азербайджаном и были размещены на 14 дней в обсерваторе на территории санатория «Талги». Подготовлены обсерваторы на 641 место (свободно 364, занято 277 мест).

В случае роста количества иностранных граждан, прибывающих на территорию РД, чтобы покинуть страну, предлагается рассмотреть возможность их размещения на 14-дневный карантин на базе созданных Минобороны России обсерваций с необходимым обеспечением. При этом в случае поддержки и согласования на межгосударственном уровне можно реализовать в РД пилотный проект по привлечению азербайджанских граждан (стихийно скапливающихся вблизи государственной границы) к сезонно-полевым и общестроительным работам. В РД планируется создать 14,5 тыс. сезонных рабочих мест в сельском хозяйстве. Реализация данного пилотного проекта позволит изменить ситуацию с нехваткой рабочих рук, обеспечить занятость иностранных граждан, ожидающих открытия границы, снизить связанную с этим социальную напряженность и криминогенную обстановку.
Всего к оказанию медицинской помощи пациентам с новой коронавирусной инфекцией (и лицам из групп риска заражения) привлечен 921 человек: из них 238 врачей, 433 средних медицинских работника и 250 представителей младшего медицинского персонала.

В качестве резерва еженедельно формировались группы медицинских работников, а также клинических ординаторов, обучающихся по терапевтическим специальностям, необходимым для оказания медицинской помощи пациентам с диагнозом COVID-19. Дистанционно по проблеме коронавирусной инфекции были обучены 150 врачей и 40 средних медицинских работников. Также в настоящее время более 1000 врачей и 800 средних медицинских работников проходят дистанционное обучение.

Правительство РФ выделило РД 340 млн руб. (101,2 млн и 238,8 млн руб.) из резервного фонда на осуществление выплат стимулирующего характера за особые условия труда и дополнительную нагрузку медицинским работникам.

Из республиканского бюджета также на указанные цели выделено 149,2 млн руб. Дополнительные выплаты врачам составят 40000 руб., среднему медицинскому персоналу 30000 руб. и младшему медицинскому персоналу - 20000 руб.

При этом расширяется круг людей, которым предоставляется поддержка: это в том числе и медицинский персонал, который оказывает специализированную медицинскую помощь пациентам с внебольничной пневмонией, врачиэпидемиологи, биологи лабораторий.

Значительный вклад в борьбе с коронавирусной инфекцией был внесен профессорско-преподавательским составом и учащимися (студентами и ординаторами) ФГБОУ В0 ДГМУ Минздрава России. За анализируемый период к оказанию медицинской помощи пациентам с признаками коронавирусной инфекции были привлечены ординаторы по профильным специальностям (117 человек) и студенты старших курсов (510 человек, в том числе 360 студентов оказывали медпомощь в так называемой красной зоне и 150 студентов - в зеленой зоне). Из резервного фонда руководством медицинского университета были выделены средства для выплат стимулирующего характера за особые условия труда всем обучающимся студентам и ординаторам, принявшим участие в борьбе с коронавирусной инфекцией.

На базе кафедры терапии ФПК ППС ФГБОУ ВО ДГму Минздрава России было организовано дистанционное повышение квалификации врачей (4408 человек) по дополнительной профессиональной программе «Актуальные вопросы профилактики, диагностики и лечения коронавирусной инфекции COVID-19». Слушателями были врачи не только РД, но и других регионов РФ.

\section{Выво $\Delta ы$}

1. По числу инфицированных COVID-19 к концу первого полугодия 2020 г. Дагестан находился на 5-м месте среди всех российских регионов. Число зараженных достигло 8132, выздоровевших - 6124; зафиксирована 391 смерть, среди умерших 70 медиков. Из 96 дней наблюдения в 35 случаях ежедневный прирост составлял более 100 случаев заражения. 
2. В эпидемический процесс за период наблюдения было вовлечено 43 муниципальных образования республики. Среди обследованных городские жители составили 59,0\%; сельские жители $-41,0 \%$.

3. Стремительно нараставшая динамика заболеваемости и летальности определила необходимость создания по инициативе Правительства РД экспертной аналитической группы, которая предложила проведение рандомизированного исследования при сравнении статистических данных, поступающих от руководителей городских и районных муниципальных образований с данными медицинских организаций Минздрава РД. Анализ выявил заметные различия с учетом территориального фактора в абсолютных и относительных величинах распространенности коронавирусной инфекции в Дагестане.

17 мая пресс-центр Минздрава РД сообщил, что коронавирусом и «внебольничной пневмонией» в Дагестане болеют 13697 человек (на тот момент в регионе официально было только 3280 больных коронавирусом). Погибли от пневмонии (без учета коронавируса) 657 человек, в том числе более 70 врачей, которые своевременно не были обеспечены необходимыми СИЗами.
4. Обнажилась также проблема тотального дефицита коечной мощности инфекционного профиля, обеспеченности лекарственными препаратами. В результате в республике были дополнительно перепрофилированы 2572 коек в 20 стационарах (из них 278 коек с ИВЛ, 700 коек - с подведенным кислородом). (формирован резерв для развертывания дополнительных 595 коек для больных внебольничной пневмонией.

5. На борьбу с коронавирусом в Республику Дагестан было направлено 4,8 млрд руб. По региону было проведено 173500 тестов. Лабораторная диагностика новой коронавирусной инфекции проводилась в 7 лабораториях, из них 3 лаборатории Роспотребнадзора, 4 лаборатории государственных медицинских организаций.

6. Значительный вклад в решении вопроса снижения заболеваемости и смертности от коронавирусной инфекции был внесен ФГБОУ ВО ДГМУ Минздрава России. К работе были привлечены ординаторы по профильным специальностям (117 человек) и студенты старших курсов (510 человек, в том числе 360 студентов оказывали медицинскую помощь в так называемой красной зоне и 150 студентов - в зеленой зоне).

\section{CBEAEHИЯ ОБ АBTOPAX}

Асхабова Луиза Магомедовна (Luisa M. Askhabova) - доктор медицинских наук, профессор, заведующая кафедрой общественного здоровья и здравоохранения ФПК ППС ФГБОУ ВО ДГМУ Минздрава России, Махачкала, Российская Федерация E-mail: louisa55@mail.ru

Сабиров Ленар Фарахович (Lenar F. Sabirov) - кандидат медицинских наук, доцент, советник Председателя Правительства Республики Дагестан по вопросам здравоохранения и социальной политике, Махачкала, Российская Федерация

E-mail: lenar.sabirov.79@mail.ru

Унтилов Геннадий Владимирович (Gennady V. Untilov) - кандидат медицинских наук, ассистент кафедры общественного здоровья и здравоохранения ФПК ППС ФГБОУ В0 ДГМУ Минздрава России, Махачкала, Российская Федерация

E-mail: ugennady@mail.ru

Гаджиева Лейла Адильгереевна (Leila A. Gadzhieva) - кандидат медицинских наук, ассистент кафедры общественного здоровья и здравоохранения ФГБОУ ВО ДГМУ Минздрава России, Махачкала, Российская Федерация

E-mail: gadjieva.leila@mail.ru

\section{ヘИТЕРАТУРA}

1. Коронавирусинфо. URL: https://koronainfo.ru/dagestan

2. ^ьвов А.К., Альховский С.В., Колобухина ^.В., Бурцева Е.И. Эти ология эпиАемической вспышки COVID-19 в г. Ухань (провинция Хубэй, Китайская Народная Республика), ассоциированной с вирусом 2019CoV (Nidovirales, Coronaviridae, Coronavirinae, Betacoronavirus, подрод Sarbecovirus): уроки эпиАемии SARS-CoV // Вопросы вирусологии. 2020. T. 65, № 1. C. 6-15. DOI: https://doi.org/10.36233/0507-4088-2020-651-6-15
3. Никифоров В.В., Суранова Т.Г., Чернобровкина Т.Я. и Ар. Новая коронавирусная инфекция (COVID-19): клинико-эпидемиологические аспекты // Архивъ внутренней медицины. 2020. Т. 10, № 2. С. 87-93. DOI: https://doi.org/10.20514/2226-6704-2020-10-2-87-93

4. Романов Б.К. Коронавирусная инфекция COVID-2019 // Без опасность и риск фармакотерапии. 2020. T. 8, № 1. C. 3-8. DOI: https:// doi.org/10.30895/2312-7821-2020-8-1-3-8

5. Статистика коронавируса в Аагестане на сегодня. URL: https:// gogov.ru/covid-19/dg

\section{REFERENCES}

1. Koronavirusinfo. URL: https://koronainfo.ru/dagestan (in Russian)

2. Lvov D.K., Alkhovsky S.V., Kolobukhina L.V., Burtseva E.I. Etiology of epidemic outbreaks COVID-19 in Wuhan, Hubei province, Chinese People Republicassociated with2019-nCoV(Nidovirales, Coronaviridae, Coronavirinae, Betacoronavirus, Subgenus Sarbecovirus): lessons of SARS-CoV outbreak. Voprosy virusologii [Problems of Virology]. 2020; 65 (1): 6-15. DOI: https:// doi.org/10.36233/0507-4088-2020-65-1-6-15 (in Russian)

3. Nikiforov V.V., Suranova T.G., Chernobrovkina T.Yu., Yankovskaya Y.D., Burova S.V. New Coronavirus Infection (Covid-19): Clinical and epidemiological aspects. Arkhiv" vnutrenney meditsiny [The Russian Archives of Internal Medicine]. 2020; 10 (2): 87-93. DOI: https://doi. org/10.20514/2226-6704-2020-10-2-87-93 (in Russian)

4. Romanov B.K. Coronavirus disease COVID-2019. Bezopasnostrisk farmakoterapii [Safety and Risk of Pharmacotherapy]. 2020; 8 (1): 3-8. DOI: https://doi.org/10.30895/2312-7821-2020-8-1-3-8 (in Russian)

5. Statistics coronavirus in Dagestan today. URL: https://gogov.ru/ covid-19/dg (in Russian) 